\title{
Lymph node metastasis in young and middle-aged papillary thyroid carcinoma patients: a SEER-based cohort study
}

\author{
Yuanchao Liư ${ }^{\dagger}$ Yizeng Wang ${ }^{\dagger}$, Ke Zhao, Dongyang Li, Zuoyu Chen, Ruoyu Jiang, Xiaoning Wang and Xianghui He* (D)
}

\begin{abstract}
Background: Lymph node metastasis (LNM) occurs frequently in young papillary thyroid carcinoma (PTC) patients, though the mortality rates are low. We aimed to analyze the relationship between age at diagnosis and LNM in PTC at a population level to elucidate the clinical behavior of PTC.

Methods: Data of adult patients with surgically treated PTC and follicular thyroid carcinoma (FTC) were identified from the Surveillance, Epidemiology, and End Results (SEER) database (2004-2015) to investigate the relationship between age and clinical characteristics by curve estimation. The adjusted odds ratio of age and LNM rate were determined.

Results: A total of 50,347 PTC $(48,166)$ and FTC (2181) (median age: 45 and 50 years, respectively) patients met the inclusion criteria; $44.5 \%$ of those with PTC $(21,428)$ had LNM. Rank-sum test analysis indicated differences in distribution of age in LNM-positive and LNM-negative PTC. The relationship between age, tumor size and LNM showed a quadratic curve in PTC. The mean tumor diameter and LNM rate correlated linearly with age in 18-59year-old patients. LNM rate decreased with age $\left(R^{2}=0.932, P<.0001\right)$, especially women $\left(R^{2}=0.951, P<.0001\right)$.

Conclusion: In young and middle-aged PTC patients, LNM may resolve spontaneously with delayed diagnosis and management. Active surveillance of low-risk PTC is justified.
\end{abstract}

Keywords: Papillary thyroid carcinoma, Age at diagnosis, Tumor size, Lymph node metastasis, SEER database

\section{Background}

In the United States (US), thyroid cancer is the most rapidly increasing cancer and more than 50,000 new cases will be diagnosed in 2019, with an increasing death rate $[1,2]$. Differentiated thyroid carcinoma (DTC), appearing mainly as papillary thyroid carcinoma (PTC) accounts for approximately $90 \%$ of the disease [3]. By the year 2019, PTC is expected to become the third most common cancer in women in the US [4].

\footnotetext{
* Correspondence: humphreyhe@163.com

†Yuanchao Liu and Yizeng Wang contributed equally to this work. Department of General Surgery, Tianjin Medical University General Hospital, 154 Anshan Road Heping District, Tianjin 300052, China
}

PTC occurs predominantly in young and middle-aged individuals, is less aggressive, and is associated with a low mortality rate. Patient age is a strong predictor of patient outcomes, and recurrence and death rates are significantly higher in older patients $[5,6]$. Age at diagnosis is incorporated into all major thyroid cancer staging systems, including the American Joint Committee on Cancer (AJCC) staging system [7, 8]. Young and middle-aged PTC patients are classified into stages I and II, regardless of local extension and metastasis.

Active surveillance in papillary thyroid microcarcinoma (PTMC) is recommended but not well accepted because of the concern of lymph node metastasis (LNM). Previously, LNM was recognized as a prognostic

C C The Author(s). 2020 Open Access This article is licensed under a Creative Commons Attribution 4.0 International License, which permits use, sharing, adaptation, distribution and reproduction in any medium or format, as long as you give appropriate credit to the original author(s) and the source, provide a link to the Creative Commons licence, and indicate if changes were made. The images or other third party material in this article are included in the article's Creative Commons licence, unless indicated otherwise in a credit line to the material. If material is not included in the article's Creative Commons licence and your intended use is not permitted by statutory regulation or exceeds the permitted use, you will need to obtain permission directly from the copyright holder. To view a copy of this licence, visit http://creativecommons.org/licenses/by/4.0/ The Creative Commons Public Domain Dedication waiver (http://creativecommons.org/publicdomain/zero/1.0/) applies to the data made available in this article, unless otherwise stated in a credit line to the data. 
indicator only in older PTC and follicular thyroid carcinoma (FTC) patients [9]. Recently, Adam et al. [10] demonstrated that in young PTC patients, the presence of cervical LNM and the number of metastatic cervical lymph nodes are associated with compromised survival. LNM predicts poor prognosis and decreased overall survival (OS) in PTC. However, LNM incidence is high while mortality is low in young patients. Therefore, the relationship among age at diagnosis, LNM, and OS is still inconclusive. It is difficult to monitor the fate of metastatic lymph nodes because lymph node status cannot be ascertained without surgery. The aim of this study was to analyze the relationship between the age at diagnosis and LNM in PTC at the population level, to elucidate the clinical behavior of PTC.

\section{Methods}

\section{SEER database}

We extracted data from the Surveillance, Epidemiology, and End Results (SEER) cancer registry maintained by the National Cancer Institute, which currently collects and publishes cancer incidence, survival data, therapy information, and clinicopathological characteristics of patients from population-based cancer registries covering approximately $34.6 \%$ of the US population.

\section{Patient selection}

We identified patients diagnosed with PTC (ICD-O-3 codes 8050, 8260-8263, 8340-8344, 8450) and FTC (ICD-O-3 codes 8290, 8330-8333, 8335) between 2004 and 2015. Variables included patient age at diagnosis, sex, race, tumor size, extrathyroidal extension (ETE), laterality, multifocality, histological variant, LNM, and distant metastasis at initial treatment.

Exclusion criteria included age $<18$ years, presence of other primary cancers, lack of pathological confirmation of cancer, did not undergo lymphadenectomy, and unknown LNM status. Patients with unknown race, tumor size, ETE, multifocality, histological variant, and distant metastasis status were excluded from multivariate logistic regression analysis.

\section{Statistical analysis}

Descriptive statistics were used to analyze patient characteristics by LNM status; continuous variables were compared using Wilcoxon rank sum tests, and categorical variables by Pearson $x^{2}$ or the exact Fisher's tests. The distribution of age at diagnosis was compared by Wilcoxon rank sum tests or Kruskal-Wallis $\mathrm{H}$ tests according to demographic and clinicopathological characteristics. The odds ratio (OR) for relationships between clinicopathological factors and LNM were calculated using multivariate logistic regression.
We further investigated the relationship of age at diagnosis with tumor size, LNM, ETE, and distant metastasis by Spearman rank correlation and curve estimation.

To analyze the trend in rate change in tumor size and LNM by age in adults with normal immunologic function, we selected PTC patients aged 18 to 59 years and classified them by sex and T stage (as per AJCC, 8th edition) [11].

To systematically analyze the contribution of age toward tumor size and LNM in PTC, multivariate analyses were performed, with age (18 to 59 years) as a categorical variable. Furthermore, to evaluate the change in protective effect of age, the age cutoffs were incrementally stepped from 21 to 57 years in 1 -yearly increments, and the adjusted OR for older age was compared across multivariate logistic regression models. The effects of the following were adjusted for in the model: sex, race, tumor size, ETE, multifocality, histology, and distant metastases.

Two-sided $P$-values <.05 were considered significant. Statistical analyses were performed using SPSS Statistics version 22 (IBM Corp., Armonk, NY, USA) and GraphPad Prism 7 (GraphPad Software, La Jolla, California, USA).

\section{Ethical approval}

We received permission to access the research data file in the SEER program from the National Cancer Institute, US (reference number 15218-Nov2017). Approval was waived by the local ethics committee, as SEER data is publicly available and de-identified.

\section{Results}

Demographic and clinical characteristics of DTC according to LNM status

A total of 50,347 surgically treated PTC $(48,166)$ and FTC (2181) patients met the inclusion criteria (women, $77.4 \%$ and White race, $82.9 \%) ; 44.5 \%$ of PTC $(21,428)$ had LNM. The median age was 45 years (range, 18-99 years) for PTC and 50 years (18-94) for FTC. The mean tumor size was $19.3 \pm 17.6 \mathrm{~mm}$ for 48,166 PTC; 15,721 (32.6\%) of PTC were small (PTMC; maximum diameter, $\leq 1 \mathrm{~cm}$ ). Table 1 presents the patient demographic and clinicopathological characteristics. For PTC, the mean age at diagnosis was lower in the LNM-positive group compared to that in the LNM-negative group (43.8 \pm 14.7 vs. $47.4 \pm 13.6$ years, respectively; $P<.0001$ ) (Fig. S1). LNM-positive and LNM-negative PTC patients differed in the following parameters: sex, tumor size, ETE, multifocality, histological variant, $\mathrm{T}$ stage, and distant metastasis (Table 2). PTC patients with male sex, Black race, small tumor size, major neck structure invasion, multifocality, columnar cell variant, T1a and T4 stage, 
Table 1 Demographic and Clinicopathological Characteristics of Thyroid Carcinoma Patients according to Lymph Node Metastasis Status

\begin{tabular}{|c|c|c|c|c|c|c|c|c|}
\hline \multirow[t]{2}{*}{ Variance } & \multicolumn{4}{|l|}{ PTC } & \multicolumn{4}{|l|}{ FTC } \\
\hline & LNM-negative & LNM-positive & Total & $\boldsymbol{P}$ value & LNM-negative & LNM-positive & Total & $\boldsymbol{P}$ value \\
\hline Age at diagnosis (mean $\pm S D), y$ & $47.4 \pm 13.6$ & $43.8 \pm 14.7$ & $45.8 \pm 14.2$ & $<.0001$ & $48.8 \pm 15.5$ & $55.3 \pm 16.3$ & $49.6 \pm 15.7$ & $<.0001$ \\
\hline Sex & & & & $<.0001$ & & & & $<.0001$ \\
\hline Male & $4349(40.3)$ & $6443(59.7)$ & 10,792 & & $470(81.3)$ & $108(18.7)$ & 578 & \\
\hline Female & $22,389(59.9)$ & $14,985(40.1)$ & 37,374 & & $1450(90.5)$ & $153(9.5)$ & 1603 & \\
\hline Race & & & & $<.0001$ & & & & .004 \\
\hline White & $22,468(56.3)$ & $17,472(43.7)$ & 39,940 & & $1599(88.7)$ & $203(11.3)$ & 1802 & \\
\hline Black & $1166(64.1)$ & $654(35.9)$ & 1820 & & $136(88.3)$ & $18(11.7)$ & 154 & \\
\hline API & $2613(48.2)$ & $2812(51.8)$ & 5425 & & 0 & 0 & 0 & \\
\hline $\mathrm{Al} / \mathrm{AN}$ & $119(38.6)$ & $189(61.4)$ & 308 & & $157(80.1)$ & $39(19.9)$ & 196 & \\
\hline Unknown & $372(55.3)$ & $301(44.7)$ & 673 & & $28(96.6)$ & $1(3.4)$ & 29 & \\
\hline Tumor size (mean \pm SD), mm & $16.1 \pm 15.2$ & $23.3 \pm 19.5$ & $19.3 \pm 17.6$ & $<.0001$ & $34.7 \pm 23.0$ & $43.9 \pm 29.0$ & $35.8 \pm 23.9$ & $<.0001$ \\
\hline $0-10$ & $11,448(72.8)$ & $4273(27.2)$ & 15,721 & & $146(89.6)$ & $17(10.4)$ & 163 & \\
\hline $11-20$ & $8195(52.8)$ & $7336(47.2)$ & 15,531 & & $352(89.3)$ & $42(10.7)$ & 394 & \\
\hline $21-40$ & $5168(43.7)$ & $6668(56.3)$ & 11,836 & & $808(91.2)$ & $78(8.8)$ & 886 & \\
\hline$>40$ & $1507(37.0)$ & $2568(63.0)$ & 4075 & & $562(83.1)$ & $114(16.9)$ & 676 & \\
\hline Unknown & $420(41.9)$ & $583(58.1)$ & 1003 & & $52(83.9)$ & $10(16.1)$ & 62 & \\
\hline ETE & & & & $<.0001$ & & & & $<.0001$ \\
\hline Localized & $23,577(65.2)$ & $12,586(34.8)$ & 36,163 & & $1693(93.0)$ & $128(7.0)$ & 1821 & \\
\hline Minor $^{a}$ & $1091(26.4)$ & $3036(73.6)$ & 4127 & & $59(61.5)$ & $37(38.5)$ & 96 & \\
\hline Strap muscles ${ }^{b}$ & $1453(30.3)$ & $3341(69.7)$ & 4794 & & $68(71.6)$ & $27(28.4)$ & 95 & \\
\hline Major neck structures ${ }^{c}$ & $373(16.8)$ & $1841(83.2)$ & 2214 & & $63(53.4)$ & $55(46.6)$ & 118 & \\
\hline Unknown & $244(28.1)$ & $624(71.9)$ & 868 & & $37(72.5)$ & $14(27.5)$ & 51 & \\
\hline Laterality & & & & .03 & & & & .55 \\
\hline One side & $26,584(55.6)$ & $21,270(44.4)$ & 47,854 & & $1914(88.1)$ & 259 (11.9) & 2173 & \\
\hline Bilateral & $154(49.4)$ & $158(50.6)$ & 312 & & $6(75.0)$ & $2(25.0)$ & 8 & \\
\hline Multifocality & & & & $<.0001$ & & & & $<.0001$ \\
\hline Absent & $15,054(62.4)$ & 9079 (37.6) & 24,133 & & 1587 (91.4) & 149 (8.6) & 1736 & \\
\hline Present & $11,387(49.1)$ & $11,814(50.9)$ & 23,201 & & $298(76.2)$ & $93(23.8)$ & 391 & \\
\hline Unknown & $297(35.7)$ & $535(64.3)$ & 832 & & $35(64.8)$ & 19 (35.2) & 54 & \\
\hline Histological Variant & & & & $<.0001$ & & & & \\
\hline Adenocarcinoma & $14,709(47.8)$ & $16,065(52.2)$ & 30,774 & & - & - & - & \\
\hline Follicular variant & $9168(71.5)$ & $3650(28.5)$ & 12,818 & & - & - & - & \\
\hline Oxyphilic cell variant & $52(56.5)$ & $40(43.5)$ & 92 & & - & - & - & \\
\hline Encapsulated variant & $209(76.0)$ & $66(24.0)$ & 275 & & - & - & - & \\
\hline Columnar cell variant & 267 (35.6) & $484(64.4)$ & 751 & & - & - & - & \\
\hline Microcarcinoma ${ }^{d}$ & $1412(85.3)$ & $244(14.7)$ & 1656 & & - & - & - & \\
\hline Unknown & $921(51.2)$ & $879(48.8)$ & 1800 & & - & - & - & \\
\hline T Stage & & & & $<.0001$ & & & & $<.0001$ \\
\hline T1a & $11,146(75.3)$ & $3652(24.7)$ & 14,798 & & $144(90.6)$ & $15(9.4)$ & 159 & \\
\hline $\mathrm{T} 1 \mathrm{~b}$ & 7497 (56.5) & $5763(43.5)$ & 13,260 & & $342(91.2)$ & $33(8.8)$ & 375 & \\
\hline $\mathrm{T} 2$ & $4641(49.2)$ & $4801(50.8)$ & 9442 & & $773(93.1)$ & $57(6.9)$ & 830 & \\
\hline T3 & $2746(36.2)$ & $4850(63.8)$ & 7596 & & $551(85.6)$ & $93(14.4)$ & 644 & \\
\hline
\end{tabular}


Table 1 Demographic and Clinicopathological Characteristics of Thyroid Carcinoma Patients according to Lymph Node Metastasis Status (Continued)

\begin{tabular}{|c|c|c|c|c|c|c|c|c|}
\hline \multirow[t]{2}{*}{ Variance } & \multicolumn{4}{|l|}{ PTC } & \multicolumn{4}{|l|}{ FTC } \\
\hline & LNM-negative & LNM-positive & Total & $\overline{P \text { value }}$ & LNM-negative & LNM-positive & Total & $\overline{P \text { value }}$ \\
\hline T4 & $373(16.8)$ & $1842(83.2)$ & 2215 & & $63(53.4)$ & $55(46.6)$ & 118 & \\
\hline Unknown & $335(39.2)$ & $520(60.8)$ & 855 & & 47 (85.5) & $8(14.5)$ & 55 & \\
\hline Distant metastasis ${ }^{\mathrm{e}}$ & & & & $<.0001$ & & & & $<.0001$ \\
\hline No & $26,497(56.1)$ & $20,698(43.9)$ & 47,195 & & $1856(90.1)$ & $205(9.9)$ & 2061 & \\
\hline Yes & $103(18.5)$ & $455(81.5)$ & 558 & & $56(50.9)$ & $54(49.1)$ & 110 & \\
\hline Unknown & $138(33.4)$ & $275(66.6)$ & 413 & & $8(80.0)$ & $2(20.0)$ & 10 & \\
\hline Total & $26,738(55.5)$ & $21,428(44.5)$ & 48,166 & & $1920(88.0)$ & $261(12.0)$ & 2181 & \\
\hline
\end{tabular}

Abbreviations: LNM Lymph node metastasis, PTC Papillary thyroid carcinoma FTC Follicular thyroid carcinoma, API Asian or Pacific Islander, Al/AN American Indian/Alaska Native, ETE Extrathyroidal extension

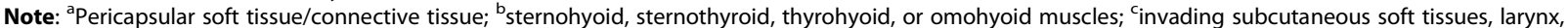
trachea, esophagus, recurrent laryngeal nerve, prevertebral fascia, encasing carotid artery, or mediastinal vessels; ${ }^{\mathrm{d}}$ labeled as microcarcinoma in the Surveillance Epidemiology, and End Results (SEER) database, there was no specific pathological subtype classification; ${ }^{{ }^{i n c l u d i n g}}$ the bone, brain, liver, and lung. Number of observations: 50,347

LNM, and distant metastasis were more frequently diagnosed at an older age (Rank sum test analysis, Table 2).

\section{Risk factors for LNM}

There was adequate information for 43,344 PTC and 2002 FTC patients to be included in the multivariate analysis. Multivariate logistic regression showed that male sex, large tumor size, ETE, multifocality, and distant metastasis significantly increased LNM risk in PTC (Table 3). In FTC, LNM risk was significantly increased with male sex, ETE, multifocality, and distant metastasis (Table 3). Importantly, age at diagnosis decreased the risk of LNM in PTC, with OR (95\% confidence interval (CI) $0.974 \quad(0.972-0.975) \quad(P<.0001)$. In contrast, for FTC, age at diagnosis was not related to the risk of LNM.

\section{Correlation analysis of age at diagnosis and tumor size, LNM, ETE, and distant metastasis in PTC patients}

We first did Spearman rank correlation analysis and results indicated that there was correlation between tumor size, LNM, ETE, distant metastasis and age at diagnosis (treated as a continuous variable, 18 to $>92$ years). Tumor size was expressed as the mean tumor diameter, and LNM, ETE, and distant metastasis as positive rates. Spearman correlation coefficients $\left(\mathrm{r}_{\mathrm{s}}\right)$ yielded was 0.307 $(P=.007),-0.266(P=.02), 0.877(P<.0001)$, and 0.751 $(P<.0001)$ respectively in PTC. To further explore the correlation between tumor size, LNM, ETE, distant metastasis and age at diagnosis. Curve estimation and regression analysis were performed. As shown in Fig. 1a-d, the relationship between tumor size and age at diagnosis fit nicely with a quadratic function $\left(R^{2}=0.815\right)$; Similar relationships were shown between LNM, ETE and age at diagnosis, $\left(R^{2}=0.843\right.$ and $R^{2}=0.905$ respectively). It is worth noting that the bottom of the curve corresponding to patients at middle age (40-60 years old). The left portion of the curve indicated that the mean tumor diameter and LNM rate decreased with age in young and middle-aged PTC patients.

\section{Correlation analysis of age at diagnosis and tumor size, LNM, ETE, and distant metastasis in FTC patients}

Although multivariate analysis of FTC patients showed no correlation between age at diagnosis and LNM, to compare with PTC patients, we also performed Spearman rank correlation and curve estimation of tumor size, LNM, ETE, distant metastasis, and age at diagnosis (treated as a continuous variable, 18 to $>90$ years) in FTC patients. Because the number of FTC patients was small and the $\mathrm{Y}$ value contained several 0 values, we used 3-yearly increments for analysis. Spearman correlation coefficient $\left(\mathrm{r}_{\mathrm{s}}\right)$ for tumor size (mean tumor diameter), LNM, ETE, and distant metastasis (positive rate) were $0.820 \quad(P<.0001), 0.909 \quad(P<.0001), 0.890 \quad(P<$ $0.0001)$, and $0.700(P<.0001)$, respectively. Curve estimation analysis results including the best match model and regression coefficients are shown in Fig. 1e-h. The relationship between tumor size, LNM, ETE, distant metastasis and age at diagnosis for FTC were totally different from that of the PTC. Further analysis of age at diagnosis and LNM was focused on PTC.

\section{Relationship between tumor size and LNM rate, and age at diagnosis in young and middle-aged PTC patients}

Statistical analysis showed that the relationship between age at diagnosis and tumor size and LNM fit a quadratic curve in all age groups of PTC patients. Biologically, young and middle-aged patients usually have normal immune function which may affect tumor growth and metastasis. We further selected patients with PTC from those aged 18-59 years to analyze the correlation 
Table 2 The Distribution of Age at Diagnosis in Thyroid Carcinoma Patients according to Demographic and Clinicopathological Characteristics

\begin{tabular}{|c|c|c|c|c|c|c|}
\hline \multirow[t]{2}{*}{ Variance } & \multicolumn{3}{|l|}{ PTC } & \multicolumn{3}{|l|}{ FTC } \\
\hline & Mean $\pm S D$, year & Median (QR), year & $\boldsymbol{P}$ value $^{\mathbf{a}}$ & Mean $\pm S D$, year & Median (QR), year & $P$ value $^{\mathbf{a}}$ \\
\hline Sex & & & $<.0001$ & & & $<.0001$ \\
\hline Male & $48.6 \pm 14.3$ & $48(20)$ & & $53.1 \pm 14.5$ & $54(19)$ & \\
\hline Female & $45.0 \pm 14.1$ & $44(20)$ & & $48.3 \pm 16.0$ & $48(23)$ & \\
\hline Race & & & $<.0001$ & & & .12 \\
\hline White & $45.8 \pm 14.3$ & $45(20)$ & & $49.6 \pm 15.7$ & $50(23)$ & \\
\hline Black & $46.6 \pm 13.7$ & $45(19)$ & & $49.9 \pm 15.0$ & $50(22)$ & \\
\hline API & $45.7 \pm 14.1$ & $45(21)$ & & - & - & \\
\hline $\mathrm{Al} / \mathrm{AN}$ & $42.6 \pm 14.5$ & $40(22)$ & & $49.9 \pm 16.2$ & $49(24)$ & \\
\hline Unknown & $42.1 \pm 13.3$ & $41(19)$ & & $42.5 \pm 14.1$ & $40(23)$ & \\
\hline Tumor size (mean \pm SD), $\mathrm{mm}$ & & & $<.0001$ & & & $<.0001$ \\
\hline $0-10$ & $47.3 \pm 13.3$ & $47(19)$ & & $48.6 \pm 13.9$ & $50(19)$ & \\
\hline $11-20$ & $45.1 \pm 13.7$ & $44(20)$ & & $47.9 \pm 14.9$ & $47(21)$ & \\
\hline $21-40$ & $44.5 \pm 15.0$ & $43(22)$ & & $47.9 \pm 15.1$ & $48(23)$ & \\
\hline$>40$ & $46.0 \pm 16.3$ & $44(24)$ & & $52.9 \pm 16.7$ & $53(26)$ & \\
\hline Unknown & $47 \pm 15.2$ & $46(22)$ & & $51.5 \pm 16.6$ & $53(27)$ & \\
\hline ETE & & & $<.0001$ & & & $<.0001$ \\
\hline Localized & $45.1 \pm 13.8$ & $44(20)$ & & $47.9 \pm 15.1$ & $48(23)$ & \\
\hline Minor $^{\mathrm{b}}$ & $46.3 \pm 14.7$ & $46(21)$ & & $57.8 \pm 16.4$ & $57.5(23)$ & \\
\hline Strap muscles ${ }^{c}$ & $46.5 \pm 14.7$ & $46(22)$ & & $53.5 \pm 16.8$ & $55(26)$ & \\
\hline Major neck structures ${ }^{d}$ & $53.2 \pm 16.7$ & $53(26)$ & & $61.3 \pm 14.3$ & $63(17)$ & \\
\hline Unknown & $47.1 \pm 15.1$ & $47(23)$ & & $60.0 \pm 15.3$ & $59(24)$ & \\
\hline Laterality & & & .49 & & & .72 \\
\hline One side & $45.8 \pm 14.2$ & $45(20)$ & & $49.6 \pm 15.7$ & $50(23)$ & \\
\hline Bilateral & $46.4 \pm 14.5$ & $45(21)$ & & $52.5 \pm 19.5$ & $48.5(33)$ & \\
\hline Multifocality & & & .01 & & & $<.0001$ \\
\hline Absent & $45.6 \pm 14.5$ & $45(21)$ & & $49.1 \pm 15.7$ & $49(23)$ & \\
\hline Present & $45.9 \pm 13.9$ & $45(20)$ & & $50.9 \pm 15.4$ & $51(21)$ & \\
\hline Unknown & $46.4 \pm 15.1$ & $45.5(21)$ & & $57.5 \pm 15.9$ & $57(24)$ & \\
\hline Histological Variant & & & $<.0001$ & & & - \\
\hline Adenocarcinoma & $44.9 \pm 14.3$ & $44(21)$ & & - & - & \\
\hline Follicular variant & $47.3 \pm 13.9$ & $47(20)$ & & - & - & \\
\hline Oxyphilic cell variant & $47.6 \pm 15.5$ & $48.5(23)$ & & - & - & \\
\hline Encapsulated variant & $46.0 \pm 12.8$ & $45(19)$ & & - & - & \\
\hline Columnar cell variant & $50.5 \pm 15.5$ & $50(23)$ & & - & - & \\
\hline Microcarcinoma ${ }^{e}$ & $47.7 \pm 13.0$ & $48(19)$ & & - & - & \\
\hline Unknown & $45.0 \pm 14.2$ & $44(20)$ & & - & - & \\
\hline T Stage & & & $<.0001$ & & & $<.0001$ \\
\hline T1a & $47.2 \pm 13.2$ & $47(19)$ & & $48.8 \pm 13.9$ & $50(18)$ & \\
\hline $\mathrm{T} 1 \mathrm{~b}$ & $44.7 \pm 13.6$ & $44(19)$ & & $47.5 \pm 15.0$ & $47(21)$ & \\
\hline $\mathrm{T} 2$ & $43.5 \pm 14.5$ & $42(21)$ & & $47.3 \pm 14.9$ & $47(22)$ & \\
\hline T3 & $45.6 \pm 15.0$ & $45(22)$ & & $51.7 \pm 16.6$ & $52(26)$ & \\
\hline T4 & $53.2 \pm 16.7$ & $53(26)$ & & $61.3 \pm 14.3$ & $63(17)$ & \\
\hline
\end{tabular}


Table 2 The Distribution of Age at Diagnosis in Thyroid Carcinoma Patients according to Demographic and Clinicopathological Characteristics (Continued)

\begin{tabular}{|c|c|c|c|c|c|c|}
\hline \multirow[t]{2}{*}{ Variance } & \multicolumn{3}{|l|}{ PTC } & \multicolumn{3}{|l|}{ FTC } \\
\hline & Mean $\pm S D$, year & Median (QR), year & $\bar{P}$ value $^{\mathbf{a}}$ & Mean $\pm S D$, year & Median (QR), year & $\boldsymbol{P}$ value $^{\mathrm{a}}$ \\
\hline Unknown & $45.6 \pm 14.6$ & $45(21)$ & & $50.4 \pm 17.0$ & $51(27)$ & \\
\hline Lymph node metastasis & & & $<.0001$ & & & $<.0001$ \\
\hline Negative & $47.4 \pm 13.6$ & $47(20)$ & & $48.8 \pm 15.5$ & $49(23)$ & \\
\hline Positive & $43.8 \pm 14.7$ & $42(22)$ & & $55.3 \pm 16.3$ & $56(24)$ & \\
\hline Distant metastasis ${ }^{\mathrm{f}}$ & & & $<.0001$ & & & $<.0001$ \\
\hline No & $45.7 \pm 14.1$ & $45(20)$ & & $48.8 \pm 15.4$ & $49(23)$ & \\
\hline Yes & $55.6 \pm 17.2$ & $58(24)$ & & $64.9 \pm 13.0$ & $67(17)$ & \\
\hline Unknown & $43.9 \pm 14.9$ & $43(22)$ & & $49.7 \pm 16.9$ & $48.5(31)$ & \\
\hline Total & $45.8 \pm 14.2$ & $45(20)$ & & $49.6 \pm 15.7$ & $50(23)$ & \\
\hline
\end{tabular}

Abbreviations: PTC Papillary thyroid carcinoma, FTC Follicular thyroid carcinoma, SD Standard deviation, QR Quartile, API Asian or Pacific Islander, Al/AN American Indian/Alaska Native, ETE Extrathyroidal extension

Note: ${ }^{a} P$ value was calculated by Wilcoxon rank sum tests or by Kruskal-Wallis $\mathrm{H}$ test; ${ }^{b}$ Pericapsular soft tissue/connective tissue; ${ }^{c}$ sternohyoid, sternothyroid, thyrohyoid, or omohyoid muscles; ${ }^{d}$ invading subcutaneous soft tissues, larynx, trachea, esophagus, recurrent laryngeal nerve, prevertebral fascia, or encasing the carotid artery or mediastinal vessels; elabeled as microcarcinoma in Surveillance, Epidemiology, and End Results (SEER) database, there was no specific

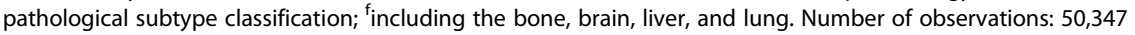

between age at diagnosis and tumor size, and between age at diagnosis and LNM. Age at diagnosis correlated linearly with tumor size and LNM; tumor size and LNM rate decreased with age $(0.825, P<.0001$ for tumor size; 0.932, $P<.0001$ for LNM) (Fig. 2a, b).

To analyze the contribution of age towards LNM in PTC, multivariate analyses were performed with age, from 18 to 59 years, as a categorical variable. The adjusted OR was calculated with reference to the 18-yearold PTC patients. The adjusted OR value was $<1$, which implied that age was a protective factor for LNM in comparison with the 18-year-old PTC patients (Fig. 2c).

To analyze changes in protective effects of age; the age cutoffs were incrementally stepped from 21 to 57 years in 1-yearly increments, and the adjusted OR for older age was compared across multivariate logistic regression models. The adjusted ORs for PTC patients aged 18-59 years are plotted in Fig. 2d. The adjusted OR for advanced age cut-off in PTC increased slightly and (statistically significant, $P<.0001$ ) in all models, implying that the protective effect of age on LNM gradually weakened with increasing age.

\section{Correlation analysis of age at diagnosis and LNM rate in PTC patients aged $18-59$ years}

To analyze the correlation between age at diagnosis and LNM rate in adults with normal immunologic function, we selected PTC patients aged 18-59 years and also classified them by $\mathrm{T}$ stage and sex. As shown in Fig. 3 and Table S1, in all T stages, LNM rates were associated inversely with age at diagnosis. The same trend was observed for sex; the LNM rate in women $\left(R^{2}=0.951\right.$, $P<.0001)$ decreased more rapidly than it did in men.

\section{Discussion}

We analyzed demographic and clinicopathological characteristics of patients with PTC and FTC, and showed that younger PTC patients had larger tumor sizes and higher LNM rates (rank-sum tests). We identified that LNM rate decreased with age in young and middle-aged adult PTC patients, implying that younger PTC patients had an increased predisposition for LNM, regardless of $T$ stage or sex.

In clinical practice, it is unjustified to follow-up a patient with preoperative diagnosis of PTC with LNM without surgery; thus, it is difficult to directly assess the unperturbed natural history of a given lesion [12]. Additionally, although radioguided occult localization technique could be used to localize the lesion site of cervical recurrences from DTC in a study [13], LNM status can still not be accurately assessed before surgery in clinical work. Here, we used population data to evaluate changes in LNM incidence with age in PTC patients aged 18-59 years. Results in this study showed that LNM rate decreases with age in PTC patients. We speculate that LNM may disappear spontaneously and tumors may shrink in size in some young and middle-aged PTC patients with delayed management. Because young and middle-aged individuals have normal immunologic responses, the activation of anti-tumor immunity could be the underlying mechanism resulting in tumor shrinkage and spontaneous resolution of LNM. Furthermore, the activation of the immune system leads to a lower risk and better survival of PTC patients.

Earlier reports of the active surveillance of PTMC cases revealed that in each follow-up period, $4.2-16.6 \%$ of the PTMC decreased in size compared to the size at initial observation [14]. In 2010, the Cancer Institute 
Table 3 Multivariate Logistic Regression Analysis of Demographic and Clinicopathological Characteristics Predictive of Lymph Node Metastasis in Thyroid Carcinoma Patients

\begin{tabular}{|c|c|c|c|c|}
\hline \multirow[t]{2}{*}{ Variance } & \multicolumn{2}{|l|}{ PTC } & \multicolumn{2}{|l|}{ FTC } \\
\hline & $\mathrm{OR}(95 \% \mathrm{Cl})$ & $\boldsymbol{P}$ value & $\mathrm{OR}(95 \% \mathrm{Cl})$ & $\boldsymbol{P}$ value \\
\hline Age at diagnosis & $0.974(0.972-0.975)$ & $<.0001$ & $0.999(0.988-1.009)$ & .82 \\
\hline Sex (female vs. male) & $0.481(0.456-0.507)$ & $<.0001$ & $0.569(0.408-0.796)$ & .001 \\
\hline Race & & $<.0001$ & & .02 \\
\hline White & 1 (reference) & & 1 (reference) & \\
\hline Black & $0.782(0.695-0.881)$ & $<.0001$ & $1.010(0.530-1.923)$ & .98 \\
\hline API & $1.191(1.114-1.274)$ & $<.0001$ & - & - \\
\hline $\mathrm{Al} / \mathrm{AN}$ & $1.714(1.300-2.261)$ & $<.0001$ & $1.883(1.193-2.971)$ & .007 \\
\hline Tumor size (mm) & & $<.0001$ & & .51 \\
\hline $0-10$ & 1 (reference) & & 1 (reference) & \\
\hline $11-20$ & $1.821(1.724-1.923)$ & $<.0001$ & $1.291(0.629-2.652)$ & .49 \\
\hline $21-40$ & $2.36(2.224-2.504)$ & $<.0001$ & $0.934(0.473-1.843)$ & .84 \\
\hline$>40$ & 2.547 (2.329-2.784) & $<.0001$ & $0.952(0.472-1.919)$ & .89 \\
\hline ETE & & $<.0001$ & & $<.0001$ \\
\hline Localized & 1 (reference) & & 1 (reference) & \\
\hline Minor $^{a}$ & $4.127(3.805-4.478)$ & $<.0001$ & $6.627(3.974-11.050)$ & $<.0001$ \\
\hline Strap muscles ${ }^{b}$ & $3.509(3.260-3.777)$ & $<.0001$ & $4.497(2.621-7.715)$ & $<.0001$ \\
\hline Major neck structures ${ }^{c}$ & $7.575(6.641-8.640)$ & $<.0001$ & $7.620(4.580-12.676)$ & $<.0001$ \\
\hline Laterality & $0.950(0.714-1.265)$ & .73 & - & 1.00 \\
\hline Multifocality & $1.661(1.590-1.735)$ & $<.0001$ & $2.816(2.012-3.941)$ & $<.0001$ \\
\hline Histology & & $<.0001$ & & - \\
\hline Adenocarcinoma & 1 (reference) & & - & \\
\hline Follicular variant & $0.371(0.353-0.391)$ & $<.0001$ & - & - \\
\hline Oxyphilic cell variant & $0.741(0.470-1.168)$ & .20 & - & - \\
\hline Encapsulated variant & $0.312(0.230-0.424)$ & $<.0001$ & - & - \\
\hline Columnar cell variant & $1.089(0.913-1.298)$ & .34 & - & - \\
\hline Microcarcinoma $^{d}$ & $0.338(0.290-0.393)$ & $<.0001$ & - & - \\
\hline Distant metastasis ${ }^{\mathrm{e}}$ & $2.787(2.137-3.635)$ & $<.0001$ & $3.768(2.195-6.467)$ & $<.0001$ \\
\hline
\end{tabular}

Abbreviations: PTC Papillary thyroid carcinoma, FTC Follicular thyroid carcinoma, OR Odds ratio, Cl Confidence interval, API Asian or Pacific Islander, Al/AN American Indian/Alaska Native, ETE Extrathyroidal extension

Note: ${ }^{a}$ Pericapsular soft tissue/connective tissue; ${ }^{b}$ sternohyoid, sternothyroid, thyrohyoid, or omohyoid muscles; ${ }^{c}$ invading subcutaneous soft tissues, larynx, trachea, esophagus, recurrent laryngeal nerve, prevertebral fascia, or encasing the carotid artery or mediastinal vessels; ${ }^{d}$ labeled as microcarcinoma in Surveillance,

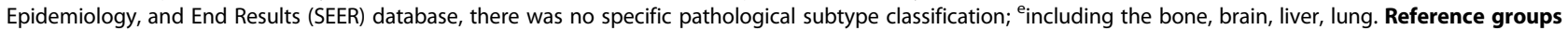
are male, white, tumor size $\leq 10 \mathrm{~mm}$, intrathyroidal tumors, one side tumors, single tumors, adenocarcinoma, and absence of distant metastasis. Number of observations: 45,346 . Bolded font indicates statistical significance

Hospital in Tokyo, Japan reported that of 300 PTMC lesions, $3 \%$ had decreased in tumor size during active surveillance [15]. Recent data show that the proportions of tumors which decreased in size was $17 \%$, with a distribution of 15,21 , and $13 \%$ for age at presentation of $\leq 40$, 41-60, and $>60$ years, respectively [16]. A retrospective observational study from Italy [17] showed that 34.9\% $(15 / 43)$ of indeterminate and $3.8 \%(2 / 52)$ of suspicious lymph nodes had disappeared during follow-up. These longitudinal data from cohorts of patients who do not undergo surgery or after thyroidectomy surgery supported that LNM may resolve spontaneously and tumors may shrink in some young and middle-aged PTC patients.

A number of studies [18-22] have examined the association between patient age at diagnosis and LNM in PTC, but the conclusions have been inconsistent. A single institution study of 1226 patients with PTMC [18] demonstrated that middle-aged and elderly patients had a lower risk of LNM compared with young patients. Similar to our study, Andrew et al. [20] found that the ipsilateral central LNM risk related to age was U-shaped with increased odds of metastases in younger and older patients. The number of cases analyzed in these studies 

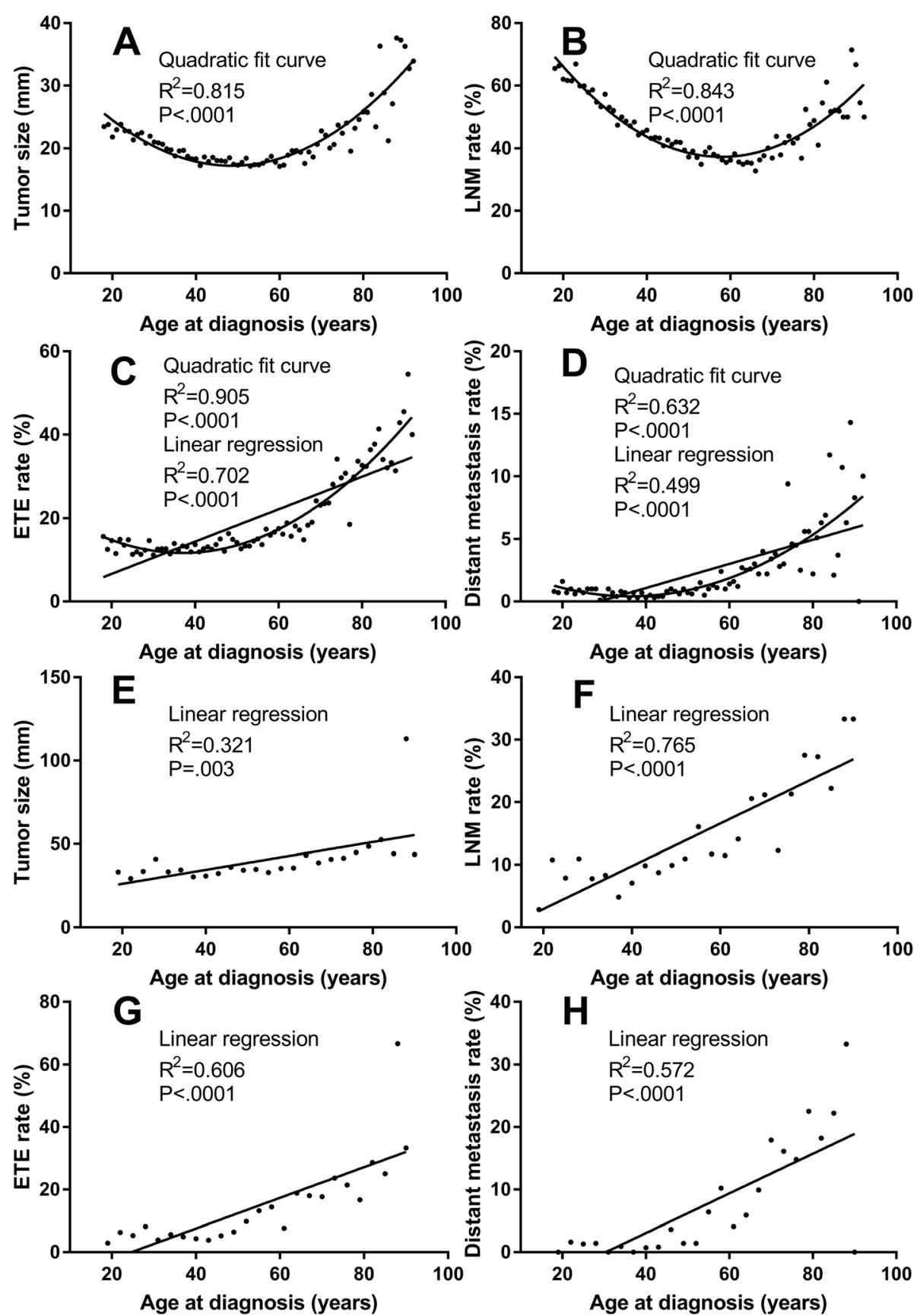

Fig. 1 Curve-fitting analysis of age at diagnosis and tumor size, lymph node metastasis (LNM), extrathyroidal extension (ETE), and distant metastasis in papillary thyroid carcinoma (PTC) and follicular thyroid carcinoma (FTC) patients. Abbreviations: ETE, extrathyroidal extension. Tumor size was represented by the mean tumor diameter; and LNM, ETE, and distant metastasis were expressed as positivity rates. Number of observations: a, 46,884; b, 48,166; c, 47,298; d, 47,753; e, 2107; f, 2181; g, 2130; h, 2171

was not large enough to derive confirmative results. A recent SEER study examined the association between patient age and LNM in 46,077 patients with PTC (1998 to 2013), [22] and showed that younger patients had an increased LNM risk regardless of T stage. However, since patients were grouped based on 10-yearly age increments, it was impossible for them to infer that LNM can disappear spontaneously with delayed surgery in immune competent young and middle-age patients.

The paradox that young PTC patients showed a higher LNM rate but a lower mortality highlights the need for further investigation into age-related differences in PTC biology, lymph node immunologic function, immunological surveillance, and host response. Previous data 


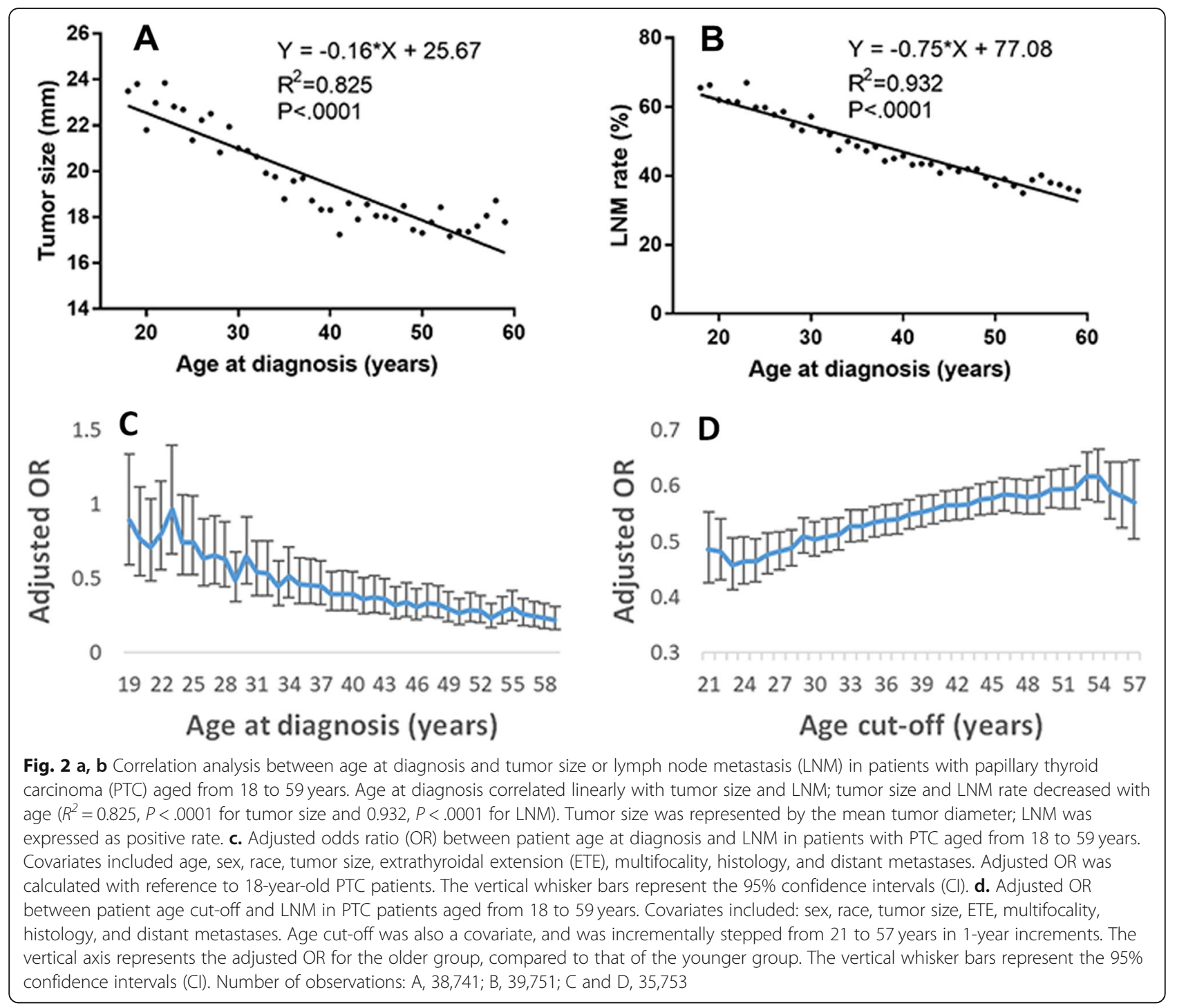

showed that positive lymph nodes were immuneactivated in PTC patients. According French et al. [23], Th1 polarization and high levels of interferon (IFN) $-\gamma^{+} /$ $\mathrm{CD}^{+} \mathrm{T}$ cells were observed in many tumor-involved lymph nodes in primary and recurrent PTC. Thus, they believed that the presence of metastases did not deter, and may have promoted, an IFN- $\gamma$ response. Proliferating lymphocytes and Th1-polarization in many tumorinvolved lymph nodes suggest that a productive antitumor response had been generated, which may impair tumor evasion [23]. Another study performed a functional analysis of tumor-associated lymph nodes and showed that $\mathrm{CD}^{+} \mathrm{T}$-cell exhaustion is incomplete and may be reversible in DTC patients, and that proliferative capacity can be largely maintained in DTC-associated T cells [24]. In addition, the good response to radioactive iodine also played a role in support of the higher LNM rate but with lower mortality rate in younger PTC patients.

The trend to an inverse relationship between incidence of LNM and patient age at diagnosis was also demonstrated in melanoma, and lung, rectum, and breast cancer [25-29]. Data from thyroid cancer, early-stage rectal cancer, and breast cancer imply that LNM of some lowrisk cancers may spontaneously disappear in immunocompetent young and middle-aged patients.

The SEER database is a powerful tool for use in clinical research, since it contains detailed information on tumor characteristics, demographic data, survival status, surgical interventions, and radiation therapy [30]. Our study included detailed demographic and clinicopathological characteristics of a cohort of 48,166 PTC and 2181 FTC patients; the data were adequately large and allowed us to perform multivariable analysis after 

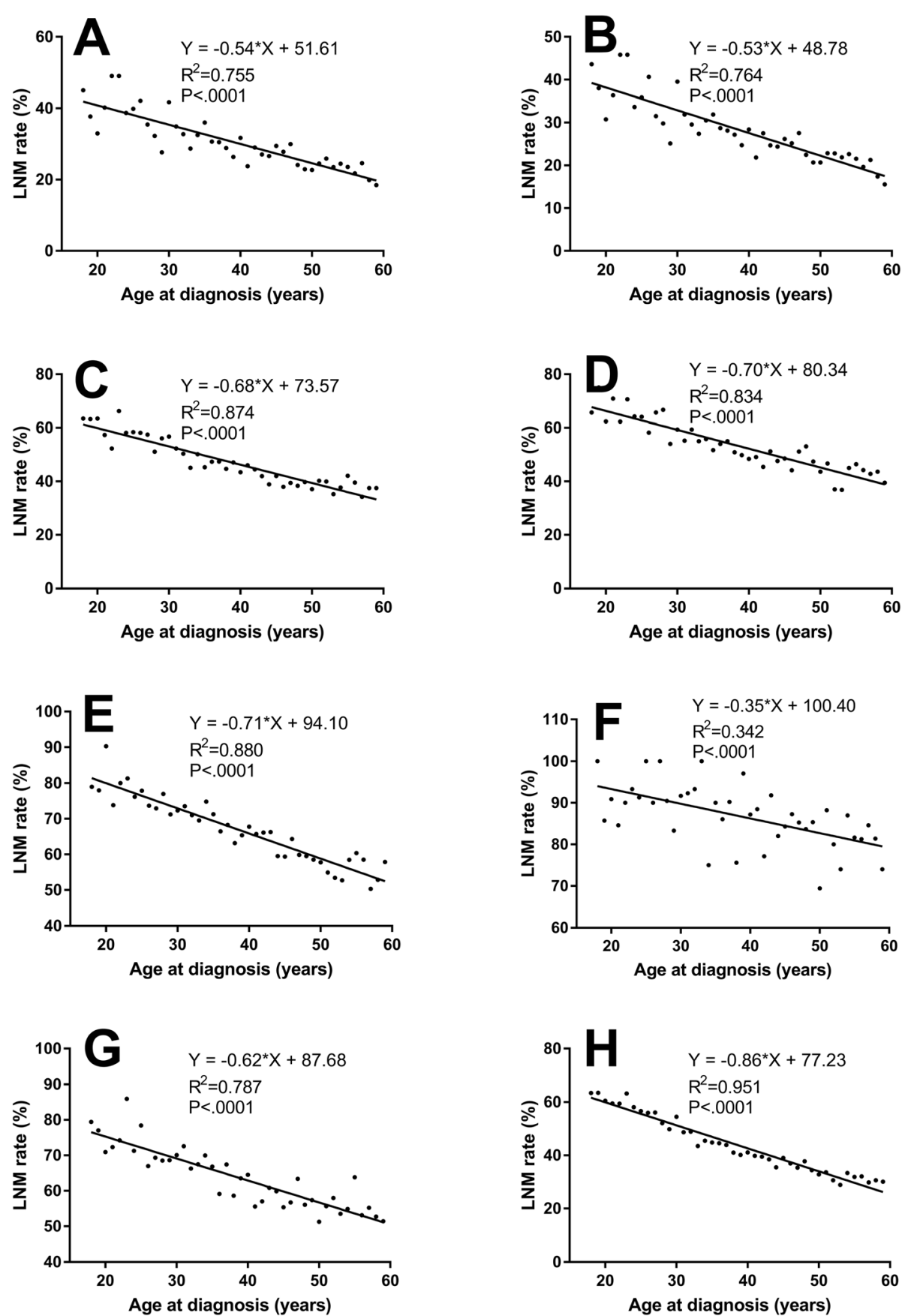

Fig. 3 Correlation analysis of age at diagnosis and LNM rate in patients with papillary thyroid carcinoma (PTC) aged from 18 to 59 , and classified by T stage and sex; a. Total papillary thyroid microcarcinoma (PTMC) patients, $N=12,796 ; \mathbf{b}$. T0 and T1a PTC patients, N=12,056; c. T1b PTC patients, $N=11,339 ;$ d. T2 PTC patients, $N=8044 ;$ e. T3 PTC patients, $N=6197 ;$ f. T4 PTC patients, $N=1397 ;$ g. Male PTC patients, $N=8341 ; \mathbf{h}$. Female PTC patients, $N=31,410$

accounting for confounders. However, there are several limitations to the current study. Since SEER only captured first line treatment data and survival status, subsequent treatment and recurrence data after surgery were not included. Our study did not include follow-up analyses, and only LNM at initial surgery was included. Data on thyroiditis, hyperthyroidism, and other thyroid diseases was lacking, so the relationship between LNM, age, and thyroid autoimmune diseases was not evaluated. Data on molecular markers and gene alterations were also not included in the SEER database, so that the influence of these factors could not be evaluated. Despite 
these limitations, the strengths of current study include a large sample size which facilitated multivariable adjustment and continuous analysis of age effects on dependent variables.

Despite a dramatic rise in incidence, mortality due to thyroid cancer has increased only slightly over the years (roughly $2 \%$ over 25 years) [31]. In recent years, physicians have increasingly begun to apply active surveillance as a valid approach to manage low-risk cancers [32, 33]. The 2015 ATA guidelines adopted active surveillance as a management option for low-risk PTMC, as an alternative to thyroidectomy [34]. Microscopic lymph node positivity conveys a much smaller risk of recurrence than do macroscopic clinically apparent loco-regional metastases [35].

\section{Conclusion}

Our study demonstrated that LNM may disappear spontaneously and tumors may become smaller in some young and middle-aged PTC patients, and from this perspective, our results imply that low-risk PTC patients may be managed with active surveillance.

\section{Supplementary information}

Supplementary information accompanies this paper at https://doi.org/10. 1186/s12885-020-6675-0.

Additional file 1: Figure S1. The distribution of age at diagnosis in thyroid cancer patients. A, Patients with papillary thyroid carcinoma (PTC); B, Patients with follicular thyroid carcinoma (FTC); C, Patients with PTC classified by lymph node status. The median age was 45 years (range, 18 99 years) in PTC and 50 (18-94) in FTC. Abbreviations: LNM, lymph node metastasis.

Additional file 2: Table 1. Correlation Analysis of Age at diagnosis and Lymph Node Metastasis Rate in Patients with PTC, Aged 18 to 59.

\section{Abbreviations}

AJCC: American joint committee on cancer; ATA: American thyroid association; DTC: Differentiated thyroid carcinoma; ETE: Extrathyroidal extension; FTC: Follicular thyroid carcinoma; LNM: Lymph node metastasis; OR: Odds ratio; OS: Overall survival; PTC: Papillary thyroid carcinoma; PTMC: Papillary thyroid microcarcinoma; SEER: Surveillance, epidemiology, and end results

\section{Acknowledgements}

The authors acknowledge the efforts of the SEER Program tumor registries in the creation of the SEER database. We thank Dr. Na Zhao and Dr. Han Ding of Tianjin Medical University General Hospital for their helpful input in preparing the manuscript. We thank Pro. Ximing Xu of Nankai University for his support and critical discussion in statistical analysis.

Part of this work was scheduled to present in poster section on November 1, 2019 at the 89th Annual Meeting of the American Thyroid Association in Chicago, IL. Presentation were not completed due to travel issues, but abstract was listed in meeting publications.

\section{Authors' contributions}

$\mathrm{XH}$ and $\mathrm{YL}$ conceived and designed the study. $\mathrm{KZ}$ and $\mathrm{YL}$ carried out data collection. YL and YW conducted data analysis. YL, DL, ZC, RJ and XW contributed to interpretation of the data. All authors were involved with the writing, review, and/or revision of the manuscript. The author (s) read and approved the final manuscript.

\section{Funding}

This work was supported in part by the National Natural Science Foundation of China (NO. 81672641). XH is supported by research grants from NSFC and the language editing of manuscript was supported by the funding body.

\section{Availability of data and materials}

We received permission to access the research data file in the SEER program from the National Cancer Institute, United States (reference number 15218Nov2017)

\section{Ethics approval and consent to participate}

We received permission to access the research data file in the SEER program from the National Cancer Institute, US (reference number 15218-Nov2017). Approval was waived by the local ethics committee, as SEER data is publicly available and de-identified.IK

\section{Consent for publication}

No individually identifiable data are presented.

\section{Competing interests}

The authors declare that they have no competing interests.

Received: 24 September 2019 Accepted: 24 February 2020

Published online: 04 March 2020

\section{References}

1. Siegel RL, Miller KD, Jemal A. Cancer statistics, 2019. CA-Cancer J Clin. 2019; 69:7-34.

2. American Cancer Society. Cancer facts \& figures 2018. Atlanta 2018. https:// www.cancer.org/research/cancer-facts-statistics/all-cancer-facts-figures/ cancer-facts-figures-2018.html.

3. Noone A, Howlader N, Krapcho M, Miller D, Brest A, Yu M, et al. SEER Cancer Statistics Review, 1975-2015 posted to the SEER web site. Natl Cancer Inst. 2018; [based on November 2017 SEER data submission]. Available from: https://seer.cancer.gov/csr/1975_2015/..

4. Aschebrook-Kilfoy B, Schechter RB, Shih YC, Kaplan EL, Chiu BC, Angelos P et al. The clinical and economic burden of a sustained increase in thyroid cancer incidence. Cancer Epidemiol Biomark Prev. 2013;22:1252-9.

5. Lim H, Devesa SS, Sosa JA, Check D, Kitahara CM. Trends in thyroid cancer incidence and mortality in the United States, 1974-2013. JAMA. 2017;317: 1338-48.

6. Haymart MR. Understanding the relationship between age and thyroid cancer. Oncologist. 2009:14:216-21.

7. Adam MA, Thomas S, Hyslop T, Scheri RP, Roman SA, Sosa JA. Exploring the relationship between patient age and cancer-specific survival in papillary thyroid cancer: rethinking current staging systems. J Clin Oncol. 2016;34: 4415-20.

8. Kazaure HS, Roman SA, Sosa JA. The impact of age on thyroid cancer staging. Curr Opin Endocrinol Diabetes Obes. 2018:25:330-4.

9. Zaydfudim V, Feurer ID, Griffin MR, Phay JE. The impact of lymph node involvement on survival in patients with papillary and follicular thyroid carcinoma. Surgery. 2008;144:1070-17 discussion 7-8.

10. Adam MA, Pura J, Goffredo P, Dinan MA, Reed SD, Scheri RP, et al. Presence and number of lymph node metastases are associated with compromised survival for patients younger than age 45 years with papillary thyroid cancer. J Clin Oncol. 2015;33:2370-5.

11. Amin MB, Edge SB, Greene FL, Byrd DR, Brookland R, Washington M, et al. AJCC cancer staging manual. 8th ed. New York: Springer; 2017.

12. Srivastava S, Koay EJ, Borowsky AD, De Marzo AM, Ghosh S, Wagner PD, et al. Cancer overdiagnosis: a biological challenge and clinical dilemma. Nat Rev Cancer. 2019;19:349-58.

13. Borso E, Grosso M, Boni G, Manca G, Bianchi P, Puccini M, et al. Radioguided occult lesion localization of cervical recurrences from differentiated thyroid cancer: technical feasibility and clinical results. Q J Nucl Med Mol Imaging. 2013:57:401-41.

14. Ito Y, Uruno T, Nakano K, Takamura Y, Miya A, Kobayashi K, et al. An observation trial without surgical treatment in patients with papillary microcarcinoma of the thyroid. Thyroid. 2003;13:381-7.

15. Sugitani I, Toda $K$, Yamada $K$, Yamamoto $N$, Ikenaga M, Fujimoto $Y$. Three distinctly different kinds of papillary thyroid microcarcinoma should be 
recognized: our treatment strategies and outcomes. World J Surg. 2010;34 1222-31.

16. Miyauchi A, Kudo T, Ito Y, Oda H, Yamamoto M, Sasai H, et al. Natural history of papillary thyroid microcarcinoma: kinetic analyses on tumor volume during active surveillance and before presentation. Surgery. 2018; 165:25-30.

17. Lamartina L, Grani G, Biffoni M, Giacomelli L, Costante G, Lupo S, et al. Risk stratification of neck lesions detected sonographically during the follow-up of differentiated thyroid cancer. J Clin Endocrinol Metab. 2016;101:3036-44.

18. Zhang L, Yang J, Sun Q, Liu Y, Liang F, Liu Z, et al. Risk factors for lymph node metastasis in papillary thyroid microcarcinoma: older patients with fewer lymph node metastases. Eur J Surg Oncol. 2016;42:1478-82.

19. Kim JY, Jung EJ, Park T, Jeong SH, Jeong CY, Ju YT, et al. Impact of tumor size on subclinical central lymph node metastasis in papillary thyroid microcarcinoma depends on age. World J Surg Oncol. 2015;13:88.

20. Thompson AM, Turner RM, Hayen A, Aniss A, Jalaty S, Learoyd DL, et al. A preoperative nomogram for the prediction of ipsilateral central compartment lymph node metastases in papillary thyroid cancer. Thyroid. 2014;24:675-82.

21. Al Afif A, Williams BA, Rigby MH, Bullock MJ, Taylor SM, Trites J, et al. Multifocal papillary thyroid Cancer increases the risk of central lymph node metastasis. Thyroid. 2015;25:1008-12.

22. Wang J, Liu J, Pan H, Jiang C, Liu S, Zhu Z, et al. Young age increases the risk of lymph node positivity in papillary thyroid cancer patients: a SEER data-based study. Cancer Manag Res. 2018;10:3867-73.

23. French JD, Kotnis GR, Said S, Raeburn CD, Mclntyre RC Jr, Klopper JP, et al. Programmed death- $1+T$ cells and regulatory $T$ cells are enriched in tumorinvolved lymph nodes and associated with aggressive features in papillary thyroid cancer. J Clin Endocrinol Metab. 2012;97:E934-43.

24. Severson JJ, Serracino HS, Mateescu V, Raeburn CD, McIntyre RC Jr, Sams SB, et al. PD-1+Tim-3+ CD8+ T lymphocytes display varied degrees of functional exhaustion in patients with regionally metastatic differentiated thyroid cancer. Cancer Immunol Res. 2015;3:620-30.

25. Page AJ, Li A, Hestley A, Murray D, Carlson GW, Delman KA. Increasing age is associated with worse prognostic factors and increased distant recurrences despite fewer sentinel lymph node positives in melanoma. Int J Surg Oncol. 2012;2012:456987.

26. Xia W, Wang A, Jin M, Mao Q, Xia W, Dong G, et al. Young age increases risk for lymph node positivity but decreases risk for non-small cell lung cancer death. Cancer Manag Res. 2018;10:41-8.

27. Meyer JE, Cohen SJ, Ruth KJ, Sigurdson ER, Hall MJ. Young age increases risk of lymph node positivity in early-stage rectal cancer. J Natl Cancer Inst. 2016;108.

28. Caywood J, Gray RJ, Hentz J, Pockaj BA. Older age independently predicts a lower risk of sentinel lymph node metastasis in breast cancer. Ann Surg Oncol. 2005;12:1061-5.

29. Bryant AS, Cerfolio RJ. Differences in outcomes between younger and older patients with non-small cell lung cancer. Ann Thorac Surg. 2008;85:1735-9 discussion 9.

30. Mehra S, Tuttle RM, Milas M, Orloff L, Bergman D, Bernet V, et al. Database and registry research in thyroid cancer: striving for a new and improved national thyroid cancer database. Thyroid. 2015;25:157-68.

31. Welch HG, Doherty GM. Saving thyroids - overtreatment of small papillary cancers. N Engl J Med. 2018;379:310-2.

32. Haymart MR, Miller DC, Hawley ST. Active surveillance for low-risk cancers a viable solution to overtreatment? N Engl J Med. 2017;377:203-6.

33. Ito $Y$, Miyauchi A, Oda H. Low-risk papillary microcarcinoma of the thyroid: a review of active surveillance trials. Eur J Surg Oncol. 2018;44:307-15.

34. Haugen BR, Alexander EK, Bible KC, Doherty GM, Mandel SJ, Nikiforov YE, et al. 2015 American Thyroid Association management guidelines for adult patients with thyroid nodules and differentiated thyroid Cancer: the American Thyroid Association guidelines task force on thyroid nodules and differentiated thyroid Cancer. Thyroid. 2016;26:1-133.

35. Randolph GW, Duh QY, Heller KS, LiVolsi VA, Mandel SJ, Steward DL, et al. The prognostic significance of nodal metastases from papillary thyroid carcinoma can be stratified based on the size and number of metastatic lymph nodes, as well as the presence of extranodal extension. Thyroid. 2012;22:1144-52.

\section{Publisher's Note}

Springer Nature remains neutral with regard to jurisdictional claims in published maps and institutional affiliations.

\section{Ready to submit your research? Choose BMC and benefit from:}

- fast, convenient online submission

- thorough peer review by experienced researchers in your field

- rapid publication on acceptance

- support for research data, including large and complex data types

- gold Open Access which fosters wider collaboration and increased citations

- maximum visibility for your research: over $100 \mathrm{M}$ website views per year

At BMC, research is always in progress.

Learn more biomedcentral.com/submissions 